\title{
Ready for a crisis? How supervisory boards affect the formalized crisis procedures of small and medium-sized family firms in Germany
}

\author{
Pedram Faghfouri • Nils D. Kraiczy • Andreas Hack • \\ Franz W. Kellermanns
}

Received: 20 January 2013/ Accepted: 26 September 2014/Published online: 30 December 2014

(C) Springer-Verlag Berlin Heidelberg 2014

\begin{abstract}
Overcoming a crisis situation in which the socioemotional wealth (SEW) of a family is at risk can be threatened by a lack of formal crisis procedures, which can increase the probability of organizational decline. Thus, not being prepared for a crisis situation may be a critical factor in the long-term survival of family firms. From a corporate governance perspective, supervisory boards may achieve higher levels of crisis readiness. Applying the resourced-based view and SEW theory, we analyze the relationship between family ownership and formalized crisis procedures in 150 small and medium-sized German firms. Our results show that formalized crisis procedures decrease as family ownership increases. Including supervisory boards in our analysis, we find a significant moderating effect of supervisory boards on the relationship between family ownership and formalized crisis procedures. Specifically, our results suggest that family firms with supervisory boards show similar levels of formalized crisis procedures as non-family firms with supervisory boards. In contrast, family firms without supervisory boards exhibit lower levels of formalized crisis procedures compared with non-family firms
\end{abstract}

P. Faghfouri · F. W. Kellermanns

Institute of Family Businesses, WHU - Otto Beisheim School of Management, Burgplatz 2, 56179 Vallendar, Germany

N. D. Kraiczy · A. Hack $(\bowtie)$

Institute of Organization and Human Resource Management, University of Bern, Engehaldenstrasse 4, 3012 Bern, Switzerland

e-mail: andreas.hack@iop.unibe.ch

A. Hack

Witten Institute for Family Business, Witten/Herdecke University, Alfred-Herrhausenstr. 50, 58448 Witten, Germany

F. W. Kellermanns

The Belk College of Business, University of North Carolina - Charlotte, 9201 University City Blvd., Charlotte, NC 28223-001, USA 
without supervisory boards. We also discuss managerial implications, limitations, and future research.

Keywords Crisis readiness $\cdot$ Formalized crisis procedures $\cdot$ Small and medium-sized firms $\cdot$ Supervisory boards $\cdot$ Family firms $\cdot$ Professionalization

JEL Classification $\mathrm{G} 33 \cdot \mathrm{G} 34 \cdot \mathrm{M} 10 \cdot \mathrm{L} 10 \cdot \mathrm{L} 20$

\section{Introduction}

The bankruptcy of a firm leads to economic loss for shareholders and problems for stakeholders. Particularly in family firms, bankruptcy results in the loss of socioemotional wealth (SEW), which has been identified as the most important reference of the owning families (Gómez-Mejía et al. 2007, 2011). The loss of a family firm might lead to grief and could be a highly traumatic experience for the family members involved (Shepherd 2009). Thus, dealing efficiently with crisis situations, which potentially lead to bankruptcy, is a major concern especially for family firms.

Prior research suggests that organizations with a higher crisis readiness can better manage crisis situations compared with unprepared organizations (Mitroff et al. 1989). Crisis readiness is defined as "a state of corporate readiness to foresee and effectively address internal and exogenous adversary circumstances with the potential to inflict a multidimensional crisis, by consciously recognizing and proactively preparing for its inevitable occurrence" (Sheaffer and Mano-Negrin 2003 , p. 575). Although the outcome of crisis readiness might not be applicable once a crisis occurs, the process of preparation itself is as important as the outcome (Kiesler and Sproull 1982) because an organization's turnaround capability can be affected by cognitive factors such as an awareness of decline, an attribution of decline, and the perceived severity of a decline (Trahms et al. 2013). Therefore, a higher degree of crisis readiness means a higher degree of cognitive rehearsal for crisis and can thus reduce the likelihood of bankruptcy in a crisis situation. Crisis readiness can be achieved, among other mechanisms, through the formalization of crisis procedures. The implementation of crisis procedures requires, for example, to professionalize rational decision-making, formalization, and adoption of external knowledge, which can be found in large established companies, many of which are often publicly traded (Stewart and Hitt 2012).

Whether standardized and formalized crisis procedures can also be found in family firms is unknown. Research often describes family firms as less professional than non-family firms (Chua et al. 2009; Martinez et al. 2007; Randøy et al. 2009; Schulze et al. 2001; Sciascia and Mazzola 2008; Westhead and Howorth 2006), which suggests less standardization and formalization. In this context, professionalization is defined as a multidimensional construct that includes the holistic transformation of organizational structures such as ownership, governance, and management (Stewart and Hitt 2012). In particular, professionalization includes the 
precise definition of organizational structures (Chandler 1990), which implies the implementation of formalized structures and procedures. A major constraint of family firms is the lack of professional management competencies (Dyer 1989), for example, competencies in strategic and financial planning (Filbeck and Lee 2000; Smyrnios and Walker 2003). Further, family firms are said to be less professional because of limited family human capital, fewer financial resources to pay competitive salaries, and the preservation of SEW (Gómez-Mejía et al. 2011). Taken together, this might result in lower crisis readiness. Recent research suggests that as a result of family involvement and the associated lack of formalization, crisis management and turnarounds are different between family and non-family firms (Cater and Schwab 2008). However, whether family firms indeed show less use of formalized crisis procedures is unknown.

Furthermore, research on the antecedents of crisis readiness is scarce. From a resource-based view (RBV) perspective, a supervisory board may have the potential to directly improve crisis readiness through the provision of external knowledge and external experience and indirectly by forcing the top management team (TMT) to implement formalized crisis procedures. Specifically, in family firms with family management, the independence of the supervisory board may be important as the monitoring role of independent supervisory boards is crucially important in a crisis situation (Trahms et al. 2013). Although some studies have investigated crisis readiness in general (e.g., Reilly 1987; Rousaki and Alcott 2006), the subject of crisis readiness depending on governance structures and the effect of supervisory boards has received insufficient scholarly attention and was never analyzed empirically (Trahms et al. 2013).

Applying SEW and RBV as theoretical perspectives, this study investigates the effect of family ownership on formalized crisis procedures as well as the direct and indirect influences of supervisory boards on this relationship. In particular, we focus on small and medium-sized firms, which in comparison to large publicly traded firms are not required to install a supervisory board because of their firm size. In doing so, this study makes multiple contributions to the existing literature. First, we add to the literature by showing that family ownership has a negative effect on formalized crisis procedures. Second, we contribute to the literature on supervisory boards in family firms as an important instrument that can be used to professionalize firms (e.g., Audretsch et al. 2013; Brenes et al. 2011). Third, we contribute to the recent literature on family firm survival (Wilson et al. 2013) by showing that implementing supervisory boards increases the level of formalized crisis procedures in family firms, which may help to explain why family firms are more likely to survive than non-family firms.

The remainder of this paper is organized as follows. After a brief review of the SEW and RBV literature in the context of professionalization and crisis readiness, we introduce family ownership as an indicator of SEW and discuss its influence on formalized crisis procedures as a measure of crisis readiness. We then analyze this relationship by considering supervisory boards as directly affecting formalized crisis procedures and as having a moderating effect on the relationship between family ownership and formalized crisis procedures. After presenting our research 
results, we conclude the paper by discussing theoretical and managerial implications and offer suggestions for future research.

\section{Theoretical framework and hypotheses}

Although crisis readiness has received attention in the field of organizational decline (Shrivastava 1988; Shrivastava et al. 1988) and organizational crisis (Pauchant and Mitroff 1992; Pearson and Clair 1998), this work has been largely descriptive and normative (Barton 1993; Greening and Johnson 1996; Markus et al. 1987; Preble 1997). Particularly, a profound theoretical reasoning to explain potential differences between the crisis readiness of family and non-family firms as well as the potential impact of supervisory boards is missing.

Crisis readiness can enhance the probability of overcoming organizational decline through standardized and formalized procedures. As SEW and RBV are two prevalent theoretical perspectives that help to explain the differences between family and non-family firms in terms of professionalization and formalized crisis procedures, we adopt these theoretical lenses to hypothesize on the potential influence of family ownership and supervisory boards on crisis readiness in family firms.

Financial objectives are important for firms, but family firms are particularly notable for the inclusion of nonfinancial objectives in their utility functions (Gómez-Mejía et al. 2011). These nonfinancial or affective utilities are also labeled SEW, which is based on the behavioral agency model (BAM). BAM combines elements of agency theory, prospect theory, and behavioral theory of firms and argues that strategic choices can be framed as a selection of alternatives that vary in potential gains or losses compared with a reference (Wiseman and Gómez-Mejía 1998). SEW is the primary point of reference in managing family firms (Gómez-Mejía et al. 2007). Family firm decisions and behavior depend on their effect on SEW preservation. SEW is a multidimensional concept that captures different aspects of affective endowment that a family bestows upon its business (Berrone et al. 2012; Cennamo et al. 2012; Gómez-Mejía et al. 2007). Examples include noneconomic aspects such as emotions (e.g., Sharma 2004; Zellweger and Astrachan 2008), values (e.g., Dyer 2003; Habbershon and Pistrui 2002), and altruism (e.g., Lubatkin et al. 2005; Miller et al. 2007). In particular, research has focused on family control and dynastic intention as two important aspects (Hauswald and Hack 2013; Zellweger and Astrachan 2008; Zellweger et al. 2012). Both aspects are dimensions of FIBER ( $\mathrm{F}$ - family control and influence, I-family members' identification with the firm, B-binding social ties, E-emotional attachment, R-renewal of family bonds to a firm through dynastic succession) that have a temporal control effect on the family firm (Berrone et al. 2012). While family control and influence have implications in the short term, the renewal of family bonds to a firm through dynastic succession has a long-term focus. Which objective predominant is, is unknown and situational. The predominant objective will rather be the one that is at risk.

RBV defines a firm as a bundle of idiosyncratic resources that is embedded in an organization (Wernerfelt 1984). Firms that possess resources and capabilities that 
are valuable, rare, difficult to imitate, imperfectly substitutable, and organized to exploit these characteristics are able to generate competitive advantage and earn superior performance (Barney 1991). RBV has been used in many studies in different fields of family firm research. The most widely known study using RBV stems from Habbershon and Williams (1999, p. 1), who define "the bundle of resources that are distinctive to a firm as a result of family involvement [...] as the 'familiness' of the firm." This unique bundle of resources can arise when a family influences a business. The interaction among a family, its members, and its business are inimitable for each family firm. Sirmon and Hitt (2003) identify five family firmspecific resources and attributes (human capital, social capital, survivability capital, patient financial capital, and governance structure) that have the potential to provide competitive advantages for family firms. In the context of crisis readiness, a lack of human and financial capital may decrease the level of professionalization.

\subsection{Family ownership and formalized crisis procedures}

Implementing instruments that increase crisis readiness has different effects on family control. First, transparency increases, which improves the monitoring of management by stakeholders. Second, managerial discretion is restricted by predefined conditions. Third, external knowledge and external support are used in crisis situations. In particular, the employment of managers external to the family in the process of professionalizing crisis management can affect SEW preservation in multiple ways. First, employing external managers implies a transfer of decision making and responsibilities outside of the family, which in turn decreases the managerial discretion of the family to influence strategic decisions (Gómez-Mejía et al. 2011). Second, experienced external managers often possess specialized knowledge from other firms and industries that is not available to family members, leading to information asymmetries (Gómez-Mejía et al. 2011). Third, predicting the behavior of external managers is also difficult, which increases behavioral uncertainty for the family members (Cruz et al. 2010). Finally, goal divergence between external managers and family members may increase the risk of opportunistic behavior by the external managers (Eisenhardt 1989; Jensen and Meckling 1976). Crisis readiness also affects the renewal of family bonds to a firm through dynastic succession because it decreases the risk of bankruptcy in a crisis situation, which in turn increases the long-term existence of the family firm. If family firms are not in a crisis situation, then family control will be more salient as a reference than dynastic intentions because of myopic behavior. Hence, family firms will not implement formalized crisis procedures, as doing so would imply a loss of family control.

From an RBV perspective, in firms with high levels of family ownership, limited family human capital and financial capital may decrease the level of professionalization. Because the human resources pool of qualified family members is limited, family firms may lack highly qualified and experienced managers (Sirmon and Hitt 2003), who are able to implement formal management structures (Dyer 1989), such as formalized crisis procedures. Furthermore, as a result of limited financial capital, family firms may not be able to employ highly qualified external managers because 
such firms cannot offer competitive salaries. In family firms with high levels of ownership, the lack of professional management may result in decreased levels of professionalization and formalization, which leads to less formalized crisis procedures. Accordingly, we hypothesize as follows:

Hypothesis 1 Family ownership is negatively related to formalized crisis procedures. Specifically, small and medium-sized firms with high family ownership levels are less formalized in terms of crisis procedures.

\subsection{Supervisory boards and formalized crisis procedures}

A supervisory board in this study refers to an independent controlling body in a twotier board structure that is comparable to an independent board of directors in a single-tier board structure. Research states that supervisory boards have an oversight role (Johnson et al. 1993). Specifically, the role of the supervisory board is to oversee strategy and monitor the managerial decisions of the TMT (Harrison 1987; Johnson et al. 1993, 1996; Withers and Hillman 2008; Zahra and Pearce 1989). Research also states that supervisory boards serve critical functions in firms, such as monitoring management on behalf of shareholders and providing valuable resources to firms, including advice, expertise, connections to environmental contingencies, and legitimacy (Hillman and Dalziel 2003; Johnson et al. 1996; Withers and Hillman 2008; Zahra and Pearce 1989). A recent review by Iwu-Egwuonwu (2010, p. 190) analyzes the empirical literature on this topic and supports this view in stating that "most findings agree that the presence of independent directors on boards of firms actually improves governance of those firms." In the crisis management process, the board of directors is responsible for initiating the formulation and implementation of crisis procedures (Preble 1997). Preble (1997, p. 777) states that "senior management and the board of directors are legally and morally responsible for initiating, overseeing and controlling contingency planning." Therefore, to prepare for a crisis and to ensure the long-term survival of a firm, its supervisory board may force the TMT to conduct contingency planning for crisis situations.

From an RBV perspective, supervisory boards provide additional resources for firms that may help to transform organizational structures into more professional structures. Board members provide different perspectives and experiences from other firms and industries. Some board members may have experienced or observed a crisis situation that has enhanced their awareness, attribution, and perception of the severity of crisis preparation (Trahms et al. 2013). For example, Mitter et al. (2012) show that supervisory boards foster a higher level of formalization and detail in planning. Additionally, supervisory boards, as a stakeholder group, possess knowledge of firm resources and are capable of controlling the planning and resource flows (Pajunen 2006). In the context of bankruptcy, the composition of the supervisory board is important to the success of the turnaround process, suggesting that more independent boards lead to more successful reorganization (Daily and Dalton 1994, 1995). 
Focusing on family firms, Lane et al. (2006, p. 152) state that controlling boards should monitor family firms and hold them accountable, as boards in family firms are expected to "ensure strategic guidance of the company, effectively monitor management, and be accountable to the company and its shareholders. "According to RBV, supervisory boards can be regarded as an additional resource that offers external knowledge to families. Studies by Corbetta and Tomaselli (1996) and Nash (1988) suggest that a supervisory board is a critical resource for family firms. Therefore, supervisory boards may have a strong influence on formalized crisis procedures of firms. Hence, we hypothesize as follows:

Hypothesis 2 The presence of supervisory boards is positively related to formalized crisis procedures. Specifically, small and medium-sized firms with supervisory boards are more formalized in terms of crisis procedures.

\subsection{The moderating role of supervisory boards}

Generally, supervisory boards are implemented to support the interests of shareholders. Thus, in family firms with family members as shareholders, supervisory boards must focus on the preservation of the families' SEW. The owners of family firms that are not in a crisis may prefer to focus on family control because their long-term survival is not at risk. However, there is a risk of losing control when implementing crisis readiness instruments because such control is more salient in a non-crisis situation. Perceptually salient references have been shown to be preferentially adopted by individuals (Heath et al. 1999; White et al. 1994). Furthermore, research shows that individuals tend to behave myopically if confronted with potential losses in the short-term but are more willing to take risks if decision evaluation periods are longer (Chrisman and Patel 2012; Thaler et al. 1997). However, because supervisory boards must focus on all FIBER dimensions, they may perceive dynastic intentions as more salient than family firm owners. The difference may be observed because supervisory board members consider a potential crisis to be a higher risk to the long-term survival of the firm and, thus, to the preservation of SEW compared with formalized crisis procedures that pose a risk in the loss of short-term family control. Hence, boards implement formalized crisis procedures to reduce the risk of bankruptcy. Furthermore, in situations that are not related to high survival risk, supervisory boards might focus more on control. For example, boards may not give decision power to banks or other stakeholders, although this power may refer more to transparency and disclosure than to decision power. From another perspective, family firms that have implemented a supervisory board may continue to weigh family influence and control as less important than the renewal of family bonds to the firm through dynastic succession, which may suggest a positive effect.

From an SEW perspective, small and medium-sized family firms benefit from supervisory boards that preserve SEW in two way. First, ownership and management positions can remain in the family firm. Second, a family's external knowledge and experience of board members from other firms and industries can improve decision making and contingency planning. Similarly, according to RBV, 
additional human resources and knowledge in the supervisory board may help families to overcome the problem of limited resources. Supervisory boards may be primarily interested in the long-term development and survival of family firms. Thus, supervisory boards may increase professionalization levels by establishing formalized crisis procedures in family firms. Accordingly, we hypothesize as follows:

Hypothesis 3 The presence of supervisory boards moderates the relationship between family ownership and formalized crisis procedures. Specifically, the existence of supervisory boards weakens the negative effect of family ownership on formalized crisis procedures.

Figure 1 illustrates the research model.

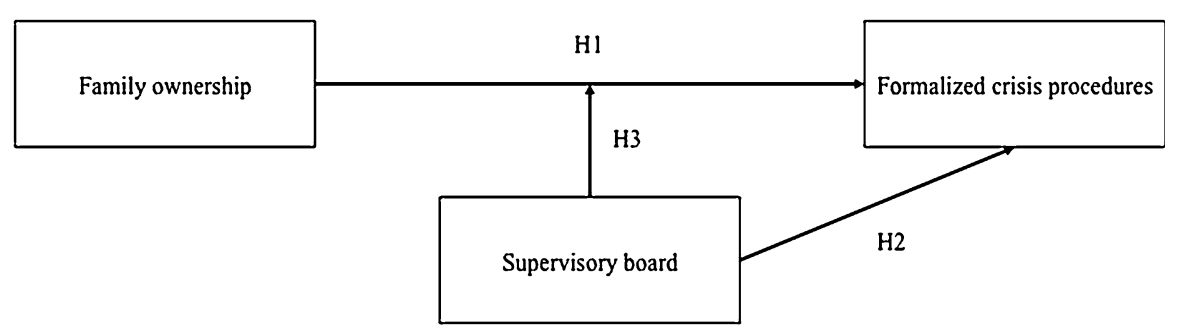

Fig. 1 Research model

\section{Methodology}

\subsection{Sample}

To test our hypotheses, we collected data from the TMTs of small and mediumsized German firms in different industries. We define small and medium-sized firms as firms with 10-499 employees and with an annual turnover of 1-50 million euros (German Federal Ministry of Economics and Technology 2014). We chose a random sample of 2000 firms whose contacts were drawn from the Amadeus database. We identified the TMT members of each firm and their personal email addresses by scanning firm websites and the Amadeus database.

We sent a personalized email to each firm's CEO that included a link to our online survey. After sending reminder emails and conducting personal phone calls, we received responses from 218 firms. The response rate of $10.9 \%$ may result from the privacy concerns and inward orientation of small and medium-sized firms (Upton et al. 2001; Zahra et al. 2004). Additionally, we assume that the TMTs of small and medium-sized firms are more involved in operational tasks and thus have less time to respond to surveys. In other recent studies focusing on small and medium-sized firms, the response rates were also low (Arend 2006; Armario et al. 2008; Lockett et al. 2008). We excluded 68 firms that did not match our definition of small and medium-sized firms from our analysis. In total, our final sample consisted 
of 150 small and medium-sized firms, resulting in a usable response rate for the purpose of our study of $7.5 \%$. The mean age of the respondents in our sample was 48.19 years, $85 \%$ of the respondents were male, and mean tenure was 10.62 years.

To control for non-response bias, we tested for differences between early and late respondents using a one-way ANOVA (analysis of variance). This approach assumes that non-respondents tend to be more similar to late respondents (Kanuk and Berenson 1975; Oppenheim 1966). Because there were no significant differences between the two groups, we concluded that non-response bias is not a concern.

We also controlled for multicollinearity issues by assessing the correlation matrix, the variance inflation factor (VIF), and the condition index. The levels of correlations between the variables were modest. All VIFs $(<2.120)$ were well below the acceptable limit of 10 (Hair et al. 2010). The condition indices $(<9.548)$ were also below the critical values suggested by Hair et al. (2010). Hence, we assumed that multicollinearity is not a significant concern.

Furthermore, we tested for potential common method bias, as suggested by Podsakoff and Organ (1986). We entered all items of the moderator and the independent, dependent, and control variables into a factor analysis and identified five factors with eigenvalues $>1.0$, which account for $65.19 \%$ of the variance. Because the first factor $(23.19 \%)$ does not explain the majority of variance, no single method factor emerged. In addition to the single-factor test for common method bias, we compared measurement models with method factor models, as recommended by Podsakoff et al. (2003). The results showed that the fit for the method factor models was significantly worse than that for the confirmatory factor analysis model. These models showed acceptable fit levels considering the sample size and the inclusion of single-item indicators. Thus, common method bias does not appear to be a significant problem in our study. Additionally, the literature suggests that common method bias cannot affect the significance of interaction effects (Evans 1985); therefore, we believe that common method bias is not a concern.

\subsection{Measures}

\subsubsection{Family ownership}

Family ownership was measured as a continuous variable. The respondents were asked to indicate how many shares are held by a family. Although we used a continuous variable in our regression analysis, a breakdown of ownership in four categories provides a better overview of our sample. In 47 firms family, ownership was $5 \%$ or less; in 10 firms, it was 6-50\%; in 15 firms, it was 51-99\%; and in 78 firms, it was $100 \%$.

\subsubsection{Formalized crisis procedures}

To measure formalized crisis procedures, we drew from a scale of strategic preparation for crisis management developed by Reilly (1989). In particular, we used three items from this scale. We also added four more items that were 
developed during expert interviews and discussions with three independent scholars and five practitioners. All items were measured on a five-point Likert-type scale. The formalized crisis procedures construct was created based on the average of the seven items. Factor analysis confirmed the uni-dimensional nature of the construct. The construct obtained an acceptable level of reliability, with a Cronbach's alpha of .882. All items appear in the Appendix.

\subsubsection{Supervisory boards}

We measured the existence of a supervisory board as a dichotomous variable by asking the respondents to answer the following yes/no question "Does your company have a supervisory board?". In total, our sample included 89 firms with a supervisory board and 61 firms without a supervisory board.

\subsubsection{Control variables}

We utilized a number of variables that may influence formalized crisis procedures. At the firm level, we controlled for firm size (employees and sales), as larger firms are to a certain extent forced to implement professional and formalized management structures and also possess more resources to implement these procedures (Stewart and Hitt 2012; Zahra et al. 2004). The mean firm size (employees) was 137.22 employees, and the mean firm size (sales) was 18.593.300 euros. Because prior research also emphasizes that industry type can affect crisis frequencies, we controlled for industry effects using two dummy variables. Industry 1 includes firms from the trade, transport, and health sectors, Industry 2 firms are from the automotive, mechanical engineering, and electronic engineering sectors. The representation of firms by industry is as follows: Industry $1(25.33 \%)$ and Industry $2(28.00 \%)$. The remaining firms operate in other industries $(46.67 \%)$. To control for concerns regarding the liability of newness concerns, we controlled for firm age (Stinchcombe 1965). The mean firm age was 49.63 years. Because firms that grow rapidly require more formalized and professionalized management structures, we also controlled for firm growth. We measured firm growth with four items including sales growth, growth in market shares, employee growth, and profitability development compared with competitors in the last 3 years. The construct obtained an acceptable level of reliability, with a Cronbach's alpha of .767. All items appear in the Appendix. Finally, we controlled for previous crisis experience, which may constitute a good reason to implement formalized crisis procedures to ensure preparation for future crises.

\section{Results}

The means, standard deviations, and zero-order correlations appear in Table 1. The correlation between family ownership and supervisory board shows a large effect and is significant $(\mathrm{r}=.652, p<.01)$. This result indicates that as family ownership increases, the tendency to have a supervisory board also increases. Table 1 also 


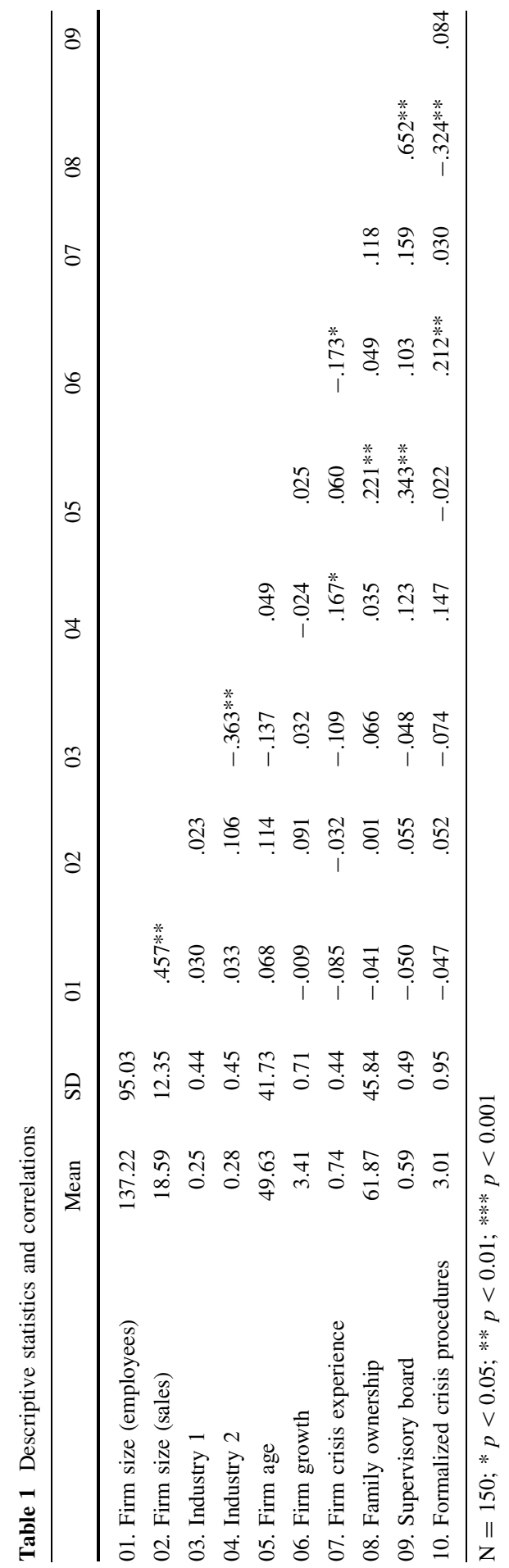


Table 2 Multiple regression analysis: dependent variable: formalized crisis procedures

\begin{tabular}{llllll}
\hline Variables & Model 1 & Model 2 & Model 3 & Model 4 & Model 5 \\
\hline Step 1: controls & & & & & \\
Firm size (employees) & -.067 & -.081 & -.063 & -.069 & -.045 \\
Firm size (sales) & .055 & .058 & .054 & .048 & .029 \\
Industry 1 & -.034 & -.011 & -.036 & -.001 & .028 \\
Industry 2 & .131 & .133 & .126 & .102 & .131 \\
Firm age & -.042 & .003 & -.060 & -.053 & -.051 \\
Firm growth & $.218^{* *}$ & $.247^{* *}$ & $.212^{*}$ & $.243^{* *}$ & $.259^{* *}$ \\
Firm crisis experience & .041 & .083 & .033 & .084 & .070 \\
Step 2: main effects & & & & & \\
Family ownership & & $-.188^{*}$ & & $-.394^{* * *}$ & $-.288^{*}$ \\
Supervisory board & & & .054 & $.318^{* *}$ & $.316^{* *}$ \\
Step 3: interaction effect & & & & & $.221^{*}$ \\
Family ownership * supervisory board & & & & & .190 \\
$\mathrm{R}^{2}$ & .076 & .107 & .079 & .154 & .132 \\
Adjusted ${ }^{2}$ & .031 & .056 & .026 & .100 & $.036^{*}$ \\
$\Delta \mathrm{R}^{2}$ (change compared to) & .076 & $.031^{*}$ & .002 & $.048^{* *}$ & $($ Model 4) \\
& & $($ Model 1) & $($ Model 1) & $($ Model 2) & F \\
F & 1.672 & $2.105^{*}$ & 1.503 & $2.841^{* *}$ & $3.267^{* * *}$ \\
\hline
\end{tabular}

Regression coefficients are reported as standardized $\beta$ values

$\mathrm{N}=150 ; * p<0.05 ; * * p<0.01 ; * * * p<0.001$

shows that family ownership and supervisory boards show positive significant correlations with firm age (family ownership: $\mathrm{r}=.221, p<.01$; supervisory boards: $\mathrm{r}=.343, p<.01$ ). A very careful assumption may be that the age of a firm plays an important role in the relationship between family ownership and supervisory boards (third variable problem or tertium quid; see Field (2013)). With increasing age, firms may become more professionally managed, and the existence of supervisory boards may become increasingly likely.

We tested our proposed hypotheses via OLS (ordinary least squares) regression analysis (Cohen et al. 2002). All independent variables were mean-centered prior to conducting the analyses. The results appear in Table 2 . In total, we tested four models. In Model 1, we entered the control variables. In Model 2, we entered the main effect, family ownership, to test Hypothesis 1. To test for Hypothesis 2, we entered the supervisory board in Model 3. To test for Hypothesis 3, we entered the interaction effect of family ownership and supervisory board to measure its effect on formalized crisis procedures in Model 5.

Model 1, which controls for firm size, industry effects, firm age, firm growth, and firm crisis experience, indicates one significant relationship. Firm growth is positively significant related to formalized crisis procedures $(\beta=.218, p<.01)$. Thus, firms that have been growing stronger the last 3 years are more formalized in terms of crisis procedures. 
To test Hypothesis 1, we entered all control variables and family ownership in Model 2. The results show that family ownership is negatively related to formalized crisis procedures, and the findings therefore support Hypothesis $1(\beta=-.188$, $\left.p<.05, \Delta \mathrm{R}^{2}=.031, p<.05\right)$.

The supervisory board variable entered in Model 3 is not significant $(\beta=.054$, n.s., $\Delta \mathrm{R}^{2}=.002$, n.s.). Hence, Hypothesis 2 is not supported.

To test Hypothesis 3, we added the interaction effect in Model 5. Hypothesis 3 predicts that family ownership has a weaker negative effect on formalized crisis procedures when a supervisory board is installed $(\beta=.221, p<.05)$. The significant change in $\mathrm{R}^{2}\left(\Delta \mathrm{R}^{2}=.036, p<.05\right)$ supports Hypothesis 3 .

To facilitate the interpretation of the moderation effect, we plotted the significant interaction in Fig. 2 (Aiken and West 1991; Cohen et al. 2002); as expected, high levels of family ownership lead to more formalized crisis procedures when a supervisory board is installed. Hence, Hypothesis 3 is supported. Figure 2 also shows that firms that have high levels of family ownership but do not have supervisory boards are less prepared for crises than firms with less family ownership without a supervisory board.

To test the robustness of our results, we conducted two post hoc tests. First, as the family ownership of more than $50 \%$ of all firms in our sample was $100 \%$, we

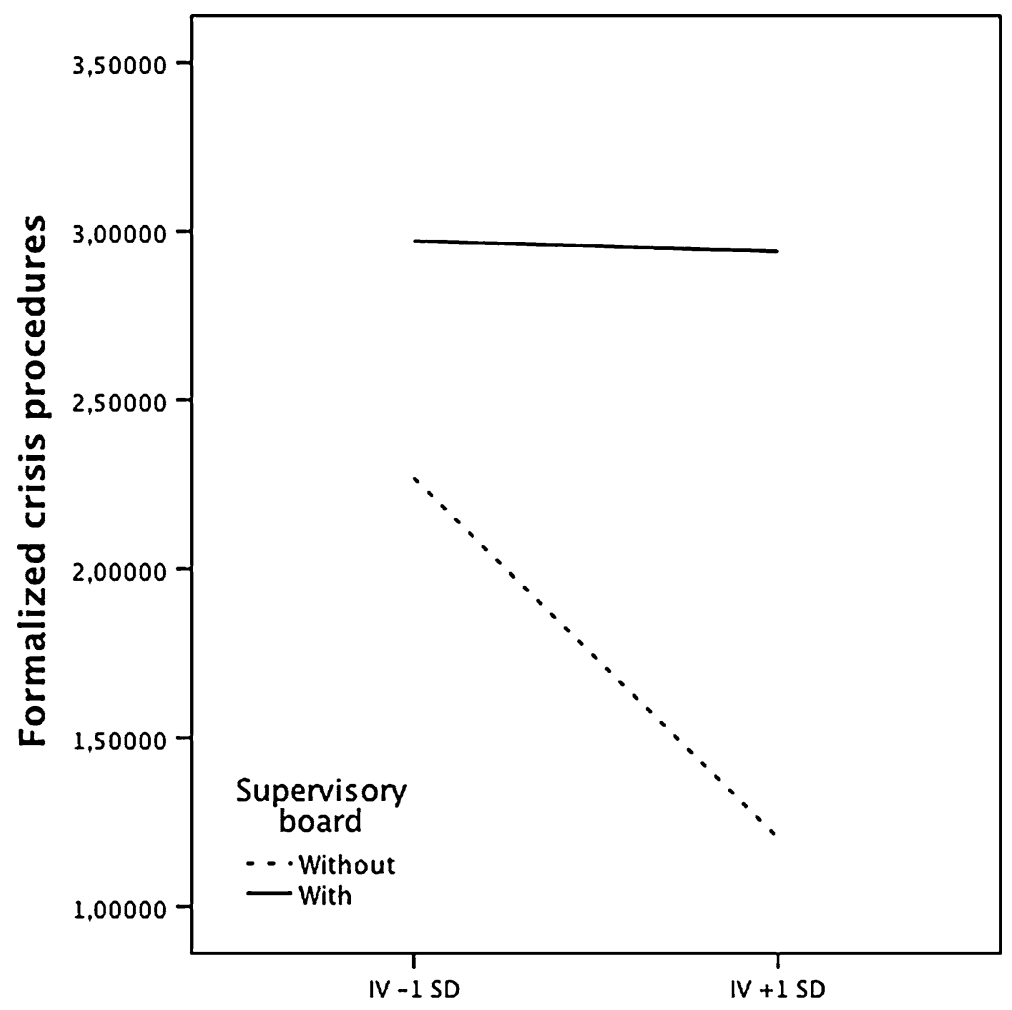

Family ownership

Fig. 2 Interaction effect of family ownership and supervisory boards 
tested for differences between these firms and firms with lower or no family ownership. We conducted an additional regression in which we replaced our continuous family ownership variable with a dummy variable $(1=100 \%$ family ownership, $0=0-99 \%$ family ownership). Although the significance levels changed partially, our hypothesized effects remained significant and robust. Second, using a one-way ANOVA, we also tested for differences in the dependent variable between these two groups. The results revealed no significant differences.

The implications of our results are discussed in the next section.

\section{Discussion}

Causes for organizational decline can be both external and internal. A recent study by Trahms et al. (2013) identifies factors such as technology change and industry decline as external causes and identifies firm structure, management, and resources as internal causes. To successfully overcome the problem of organizational decline, Trahms et al. (2013) suggest strategic leadership as one important factor, which includes having a supervisory board with independent members. In another recent study, Wilson et al. (2013) find that family firms are significantly less likely to fail than non-family firms are. The authors identify board characteristics as critical factors for firm survival. Consistent with these studies, our study emphasizes the important function of supervisory boards in preparing for a crisis in family firms.

Our results support the literature describing family firms as less formalized. For example, De Massis et al. (2015) show that the innovation process in family firms is less formalized than that in non-family firms, which may lead to lower innovativeness. Family firms are also less formalized in terms of human resource practices (de Kok and den Hartog 2006; Reid and Adams 2001). Supporting Hypothesis 1, our results show that firms with high levels of family ownership are less professionalized and formalized in terms of crisis procedures. These lower professionalization levels may result from a lack of management resources within families and an aversion to employing external managers to retain control within the family and to preserve SEW. These behaviors of family firms may protect their SEW in terms of family influence and control in the short term; however, such behaviors pose a long-term threat to the SEW dimension of the renewal of family bonds to a firm through dynastic succession because these behaviors reduce crisis readiness. Thus, our study provides a differentiated view of SEW dimensions regarding their temporal effects on family firms. Although the outcomes of crisis preparations, such as formalized crisis procedures, may not be applicable once a specific crisis situation occurs, the process of preparation itself has been identified as an important outcome (Kiesler and Sproull 1982) because it increases the awareness of decline, the attribution of decline, and the perceived severity decline, which have been identified as positively affecting crisis situations (Trahms et al. 2013). For family firms, formalized crisis procedures are particularly important because these firms aim to preserve SEW (Berrone et al. 2012; Gómez-Mejía et al. 2007, 2011).

To overcome a lack of professional management, it was hypothesized that supervisory boards are beneficial for small and medium-sized firms. However, our 
results do not support Hypothesis 2. Although our results show that supervisory boards generally increase the level of formalized crisis procedures in small and medium-sized firms, the findings are statistically not significant. This relationship thus requires more fine-grained analysis. As the moderation analysis shows, supervisory boards have a more positive effect on formalized crisis procedures in family firms compared with non-family firms. One explanation for this result may be that the shareholders of non-family firms have forced management, as a result of greater principal agent problems, to implement more professional and formalized structures to reduce information asymmetries, which may improve their position as agents. Following this assumption, the implementation/existence of a supervisory board may not necessarily increase the formalization of crisis procedures.

This situation differs for family firms. In firms with high family ownership levels, supervisory boards help to increase the level of formalized crisis procedures, thus supporting Hypothesis 3. It appears that supervisory boards can balance the lack of professional management in family firms in the context of crisis through the experience and knowledge of supervisory board members. Without transferring ownership or management positions to those external to the family, family firms can benefit from the external knowledge of supervisory board members. Thus, supervisory boards constitute a proper governance instrument that considers the importance of SEW preservation in family firms. The implementation of a supervisory board in small and medium-sized family firms may also help to explain why family firms are more likely to survive than non-family firms are (Wilson et al. 2013). By supporting the existing literature focusing on the professionalization of family firms, our results contribute to the assumption that supervisory boards are beneficial for increasing the professionalization of family firms (Audretsch et al. 2013; Brenes et al. 2011).

From a theoretical perspective, our study contributes to SEW theory. Our results indicate that in certain situations, an order of preferences among the FIBER dimensions exists. Thus, not all FIBER dimensions are considered similarly in the hierarchy of family objectives; rather, single dimensions will have a stronger effect on the behavior of the family depending on contextual and temporal influences. This finding implies that SEW orientation must be considered in future research in the context of the governance structures. Furthermore, the FIBER dimensions that families perceive as being at risk will have a stronger effect than the other dimensions.

\section{Limitations and implications for future research}

We hope to encourage future research by discussing several limitations of this study. First, including only small and medium-sized German firms in the sample raises the question of generalizability. Supervisory boards in Germany are independent controlling bodies with a two-tier board structure, whereas countries such as the United States, Switzerland, or the UK have different governance structures, including a single-tier board structure in which management and control are not always independent. As a result, other researchers may seek to replicate the findings in countries with different governance structures or in different cultural 
environments (Hofstede 2001) to identify potential country-specific influences (Miller et al. 2009).

Second, we used self-reported data from CEOs as key informants. Obtaining comprehensive objective data from small and medium-sized firms, which are often not publicly traded and reluctant to report firm data to protect privacy, can be difficult and justifies the use of subjective self-reported measures. Indeed, such measures are common when analyzing small and medium-sized firms (e.g., Kraiczy et al. 2014b; Wallace et al. 2010), as self-assessments show high correlation with objective data (e.g., Dess et al. 1990; Ling and Kellermanns 2010).

Third, we measured family influence by only assessing family ownership levels. Although we believe this family firm variable is an appropriate and frequently used indicator of family influence (e.g., Miller et al. 2010), other family firm measures may reveal additional insights in this context, such as the ratio of family members in the TMT (Kraiczy et al. 2014a) or FIBER components (Berrone et al. 2012). Berrone et al. (2012) proposed operationalizing this concept using five dimensions known as FIBER: (F) family control and influence, (I) family members' identification with the firm, (B) binding social ties, (E) emotional attachment, and (R) the renewal of family bonds to a firm through dynastic succession. Following these content elements, family firms may show different levels of SEW depending on the level of family ownership. Future research may test this concept directly to measure the degree of SEW in a firm and its effect on crisis readiness. Accordingly, we encourage future research to use various additional variables to measure family influence and SEW to consider the heterogeneity of family firms.

Fourth, the existence and use of formalized crisis procedures in particular and the professionalization of family firms in general may also be affected by the composition of supervisory boards. For example, supervisory boards with family members may have a different effect on decision-making compared with supervisory boards with independent members because family members are often also owners and are thus affected by SEW. Furthermore, the education, industry and work experiences of independent board members differ from those of family members, which may affect problem evaluations and solutions. We encourage future research to analyze the composition of supervisory boards in the context of crisis management and professionalization to further extend the understanding of the role of independent board members in family firms (Wilson et al. 2013).

Fifth, because we used the existence of a supervisory board as a moderating variable and because the moderating variable is significant, we may expect that the marginal effect of supervisory boards on formalized crisis procedures is valid for all values of family ownership. However, this marginal analysis has not been conducted and should thus be performed in future research (Brambor et al. 2006).

Sixth, family human capital and financial capital may affect the professionalization level of family firms and, thus, the use of formalized crisis procedures. In this study, we were unable to control for these effects. Hence, we suggest that future research include human capital and financial capital variables as control variables.

Finally, we were unable to control for the functions of the supervisory boards. It may not be sufficient to consider whether a firm has a supervisory; it may be necessary to examine how its board works. Hence, future research is encouraged to 
consider different functions of supervisory boards (e.g., control vs. advice functions) to gain a better understanding of the influence of supervisory boards on the degree of using formalized crisis procedures.

\section{Managerial implications}

Our study shows that family owners have a negative influence on the likelihood of implementing formalized crisis procedures. This result is critical because research suggests that preparing for a crisis is important for organizations (Mitroff et al. 1989; Reilly 1989) and enhances the long-term survival of firms. Hence, organizations should prepare for potential crisis scenarios.

Additionally, this finding applies even more to family firms that focus on the renewal of family bonds to a firm through dynastic succession. Although crisis readiness may reduce family influence and control in the short term, it increases the long-term survival and, in turn, the possibility of an internal family succession. Firms experiencing a crisis may not necessarily replace their TMT to accomplish a successful turnaround (Winn 1997). Indeed, Winn (1997) shows that TMT replacement in a crisis situation enhances the likelihood of organizational failure. To avoid being punished by stakeholders during a crisis, it is important to be trustworthy and professional prior to a crisis. Crisis readiness may be an important factor in signaling that the management is prepared for a crisis or has at least been engaged in future scenario planning. Preparing for crises in a family firm is an authentic signal to stakeholders because it may indicate a decrease in family influence and control; such preparation also increases transparency and, in turn, the possibility of family internal succession in the long term.

Additionally, our results show that supervisory boards are an important instrument in the professionalization of family firms in terms of formalized crisis procedures, which may contribute to the long-term preservation of the family values.

With regard to the members of the supervisory board in family firms, our study suggests that board members familiarize themselves with the topic of crisis readiness because it has not yet been professionally implemented in many family firms. Furthermore, supervisory board members should understand the different motives of family firms. This understanding is not only important from a theoretical perspective but may also have practical implications for the management; indeed, as observed in this study, it may have practical implications for crisis readiness. It is important to understand that family firms that are more focused on maintaining family influence and control are likely to be less prepared for a crisis. With respect to the FIBER dimensions, supervisory board members must be aware of their responsibility to secure all of the dimensions. Therefore, board members need to focus on the temporal implication of each dimension and the long-term orientation because family managers may behave rather myopically with a focus on family influence and control (Chrisman and Patel 2012). When implementing formalized crisis procedures, supervisory boards need to clarify to family managers that they secure the renewal of family bonds to a firm through dynastic succession and that 
family influence and control are only slightly affected. Particularly in a crisis situation, formalized crisis procedures protect family influence and control.

For stakeholders of family firms, particularly external investors, our study suggests to control for the implementation of crisis readiness systems because such systems are not self-evident. In addition, implementing a supervisory board may increase the likelihood that a family firm will act more professional. Hence, ratings for these firms may be higher. However, the implementation of a supervisory board is always valuable for a firm.

\section{Conclusion}

This study investigates the role of supervisory boards in small and medium-sized German firms in the context of crisis readiness. In firms with supervisory boards, family ownership levels do not affect formalized crisis procedures; conversely, in firms without supervisory boards, the level of formalized crisis procedures is lower in firms with high family ownership levels. Our results support research suggesting that family firms are less professional and formalized. In addition, our study indicates that supervisory boards are an instrument to overcome lower professional levels in terms of formalized crisis procedures in family firms.

\section{Appendix}

See Table 3.

Table 3 Scale items and reliabilities

\begin{tabular}{ll}
\hline Construct & Cronbach's \\
$\alpha$ & $\alpha$ \\
\hline
\end{tabular}

Formalized crisis procedures

Please indicate your level of agreement or disagreement with the following statements:

External and internal risks and threats, which may jeopardize the achievement of company goals, are set out in writing

In my company measures have been introduced to prevent successor problems due to the unexpected loss of important specialists and top executives (e.g. by continuously identifying suitable potential deputies and successors)

In my company critical thresholds have been determined, and when these are exceeded, appropriate contingency plans are put into action

In my company a scenario-based plan exists whereby positive as well as negative scenarios are considered

My company has provided instructions about how to respond if a news reporter were to ask an employee about something happening at the organization

The crisis management plans, tactics, and tools available at my company are adequate to deal with most crises my organization might encounter

If my company were involved in a crisis, there are adequate instructions available to provide crisis management guidance for most employees 
Table 3 continued

\begin{tabular}{ll}
\hline Construct & Cronbach's \\
$\alpha$ & $\alpha$ \\
\hline
\end{tabular}

Firm growth

How would you rate your performance compared to your competitors in the last three years in terms of...

...sales growth

...growth in market shares

...employee growth

...profitability development

\section{References}

Aiken LS, West SG (1991) Multiple regression: testing and interpreting interactions. Sage Publications, Newbury Park

Arend RJ (2006) SME: supplier alliance activity in manufacturing: contingent benefits and perceptions. Strateg Manag J 27:741-763

Armario JM, Ruiz DM, Armario EM (2008) Market orientation and internationalization in small and medium-sized enterprises. J Small Bus Manag 46:485-511

Audretsch DB, Hülsbeck M, Lehmann EE (2013) Families as active monitors of firm performance. J Fam Bus Strateg 4:118-130

Barney JB (1991) Firm resources and sustained competitive advantage. J Manag 17:99-120

Barton L (1993) Crisis in organizations: managing and communicating in the head of chaos. SouthWestern, Cincinnati

Berrone P, Cruz C, Gómez-Mejía LR (2012) Socioemotional wealth in family firms: theoretical dimensions, assessment approaches, and agenda for future research. Fam Bus Rev 25:258-279

Brambor T, Clark WR, Golder M (2006) Understanding interaction models: improving empirical analyses. Polit Anal 14:63-82

Brenes ER, Madrigal K, Requena B (2011) Corporate governance and family business performance. J Bus Res 64:280-285

Cater J, Schwab A (2008) Turnaround strategies in established small family firms. Fam Bus Rev 21:31-50

Cennamo C, Berrone P, Cruz C, Gómez-Mejía LR (2012) Socioemotional wealth and proactive stakeholder engagement: why family-controlled firms care more about their stakeholders. Entrep Theory Pract 36:1153-1173

Chandler AD (1990) Scale and scope: the dynamics of industrial capitalism. Harvard University Press, Cambridge

Chrisman JJ, Patel PC (2012) Variations in R\&D investments of family and nonfamily firms: behavioral agency and myopic loss aversion perspectives. Acad Manag J 55:976-997

Chua JH, Chrisman JJ, Bergiel EB (2009) An agency theoretic analysis of the professionalized family firm. Entrep Theory Pract 33:355-372

Cohen J, Cohen P, West SG, Aiken LS (2002) Applied multiple regression/correlation analysis for the behavioral sciences. Lawrence Erlbaum Associates, Mahwah

Corbetta G, Tomaselli S (1996) Boards of directors in Italian family businesses. Fam Bus Rev 9:403-421

Cruz CC, Gómez-Mejía LR, Becerra M (2010) Perceptions of benevolence and the design of agency contracts: CEO-TMT relationships in family firms. Acad Manag J 53:69-89

Daily CM, Dalton DR (1994) Bankruptcy and corporate governance: the impact of board composition and structure. Acad Manag J 37:1603-1617

Daily CM, Dalton DR (1995) CEO and director turnover in failing firms: an illusion of change? Strateg Manag J 16:393-400

de Kok J, den Hartog D (2006) High performance work systems, performance and innovativeness in small firms. EIM Business and Policy Research, Zoetermeer 
De Massis A, Frattini F, Pizzurno E, Cassia L (2015) Product innovation in family versus nonfamily firms: an exploratory analysis. J Small Bus Manag 53:1-36

Dess GG, Ireland RD, Hitt MA (1990) Industry effects and strategic management research. J Manag 16:7-27

Dyer WG (1989) Integrating professional management into a family owned business. Fam Bus Rev 2:221-235

Dyer WG (2003) The family: the missing variable in organizational research. Entrep Theory Pract 27:401-416

Eisenhardt KM (1989) Agency theory: an assessment and review. Acad Manag Rev 14:57-74

Evans MG (1985) A Monte Carlo study of the effects of correlated method variance in moderated multiple regression analysis. Organ Behav Hum Decis Process 36:305-323

Field A (2013) Discovering statistics using IBM SPSS statistics. SAGE publications Ltd., London

Filbeck G, Lee S (2000) Financial management techniques in family businesses. Fam Bus Rev 13:201-216

German Federal Ministry of Economics and Technology (2014) SME policy. Federal Ministry of Economics and Technology. http://www.bmwi.de/EN/Topics/Economy/sme-policy.html. Accessed 30 Oct 2014

Gómez-Mejía LR, Cruz C, Berrone P, De Castro J (2011) The bind that ties: socioemotional wealth preservation in family firms. Acad Manag Ann 5:653-707

Gómez-Mejía LR, Haynes KT, Núñez-Nickel M, Jacobson KJL, Moyano-Fuentes J (2007) Socioemotional wealth and business risks in family-controlled firms: evidence from Spanish olive oil mills. Adm Sci Q 52:106-137

Greening DW, Johnson RA (1996) Do managers and strategies matter? J Manag Stud 33:25-51

Habbershon TG, Pistrui J (2002) Enterprising families domain: family-influenced ownership groups in pursuit of transgenerational wealth. Fam Bus Rev 15:223-237

Habbershon TG, Williams ML (1999) A resource-based framework for assessing the strategic advantages of family firms. Fam Bus Rev 12:1-25

Hair JF, Black WC, Babin BJ, Anderson RE (2010) Multivariate data analysis. Prentice Hall, Upper Saddle River

Harrison JR (1987) The strategic use of corporate board committees. Calif Manag Rev 30:109-125

Hauswald H, Hack A (2013) Impact of family control/influence on stakeholders' perceptions of benevolence. Fam Bus Rev 26:356-373

Heath C, Larrick RP, Wu G (1999) Goals as reference points. Cogn Psychol 38:79-109

Hillman AJ, Dalziel T (2003) Boards of directors and firm performance: integrating agency and resource dependence perspectives. Acad Manag Rev 28:383-396

Hofstede G (2001) Culture's consequences: comparing values, behaviors, institutions, and organizations across nations. Sage Publications, Thousand Oaks

Iwu-Egwuonwu RC (2010) Some empirical literature evidence on the effects of independent directors on firm performance. J Econ Int Financ 2:190-198

Jensen MC, Meckling WH (1976) Theory of the firm: managerial behavior, agency costs and ownership structure. J Financ Econ 3:305-360

Johnson JL, Daily CM, Ellstrand AE (1996) Boards of directors: a review and research agenda. J Manag 22:409-438

Johnson RA, Hoskisson RE, Hitt MA (1993) Board of director involvement in restructuring: the effects of board versus managerial controls and characteristics. Strateg Manag J 14:33-50

Kanuk L, Berenson C (1975) Mail surveys and response rates: a literature review. J Mark Res 12:440-453

Kiesler S, Sproull L (1982) Managerial response to changing environments: perspectives on problem sensing from social cognition. Adm Sci Q 27:548-570

Kraiczy ND, Hack A, Kellermanns FW (2014a) New product portfolio performance in family firms. J Bus Res 67:1065-1073

Kraiczy ND, Hack A, Kellermanns FW (2014b) What makes a family firm innovative? CEO risk-taking propensity and the organizational context of family firms. J Prod Innov Manag. doi:10.1111/jpim. 12203

Lane S, Astrachan J, Keyt A, McMillan K (2006) Guidelines for family business boards of directors. Fam Bus Rev 19:147-167

Ling Y, Kellermanns FW (2010) The effects of family firm specific sources of TMT diversity: the moderating role of information exchange frequency. J Manag Stud 47:322-344 
Lockett A, Wright M, Burrows A, Scholes L, Paton D (2008) The export intensity of venture capital backed companies. Small Bus Econ 31:39-58

Lubatkin MH, Schulze WS, Ling Y, Dino RN (2005) The effects of parental altruism on the governance of family-managed firms. J Organ Behav 26:313-330

Markus AA, Bromiley P, Goodman R (1987) Preventing corporate crises: stock market losses as a deterrent to the production of hazardous products. Columbia J World Bus 23:33-42

Martinez J, Stohr B, Quiroga B (2007) Family ownership and firm performance: evidence from public companies in Chile. Fam Bus Rev 20:83-94

Miller D, Le Breton-Miller I, Lester RH (2010) Family ownership and acquisition behavior in publiclytraded companies. Strateg Manag J 31:201-223

Miller D, Le Breton-Miller I, Lester RH, Cannella AA (2007) Are family firms really superior performers? J Corp Financ 13:829-858

Miller D, Lee J, Chang S, Le Breton-Miller I (2009) Filling the institutional void: the social behavior and performance of family vs non-family technology firms in emerging markets. J Int Bus Stud 40:802-817

Mitroff II, Pauchant T, Finney M, Pearson C (1989) Do (some) organizations cause their own crises? The cultural profiles of crisis-prone vs. crisis-prepared organizations. Organ Environ 3:269-283

Mitter C, Duller C, Feldbauer-Durstmüller B (2012) The impact of the family's role and involvement in management and governance on planning: evidence from Austrian medium-sized and large firms. Int J Bus Res 12:56-68

Nash JM (1988) Boards of privately held companies: their responsibilities and structure. Fam Bus Rev $1: 263-269$

Oppenheim AN (1966) Questionnaire design, interviewing and attitude measurement. Free Press, New York

Pajunen K (2006) Stakeholder influences in organizational survival. J Manag Stud 43:1261-1288

Pauchant TC, Mitroff II (1992) Transforming the crisis prone organization. Preventing individual, organizational and environmental tragedies. Jossey-Bass, San Francisco

Pearson CM, Clair JA (1998) Refraiming crisis management. Acad Manag Rev 23:59-76

Podsakoff PM, MacKenzie SB, Jeong-Yeon L, Podsakoff NP (2003) Common method biases in behavioral research: a critical review of the literature and recommended remedies. J Appl Psychol 88:879-903

Podsakoff PM, Organ DW (1986) Self-reports in organizational research: problems and prospects. J Manag 12:531-544

Preble JF (1997) Integrating the crisis management perspective into the strategic management process. J Manag Stud 34:769-791

Randøy T, Dibrell C, Craig J (2009) Founding family leadership and industry profitability. Small Bus Econ 32:397-407

Reid RS, Adams JS (2001) Human resource management-a survey of practices within family and nonfamily firms. J Eur Ind Train 25:310-320

Reilly AH (1987) Are organizations ready for crisis? A managerial scorecard. Columbia J World Bus 22:79-88

Reilly AH (1989) Strategic preparation for crisis management in the banking industry. Dissertation, Northwestern University

Rousaki B, Alcott P (2006) Exploring the crisis readiness perceptions of hotel managers in the UK. Tour Hosp Res 7:27-38

Schulze WS, Lubatkin MH, Dino RN, Buchholtz AK (2001) Agency relationships in family firms: theory and evidence. Organ Sci 12:99-116

Sciascia S, Mazzola P (2008) Family involvement in ownership and management: exploring nonlinear effects on performance. Fam Bus Rev 21:331-345

Sharma P (2004) An overview of the field of family business studies: current status and directions for the future. Fam Bus Rev 17:1-36

Sheaffer Z, Mano-Negrin R (2003) Executives' orientations as indicators of crisis management policies and practices. J Manag Stud 40:573-606

Shepherd DA (2009) Grief recovery from the loss of a family business: a multi- and meso-level theory. J Bus Ventur 24:81-97

Shrivastava P (1988) Editorial: industrial crisis management: learning from organizational failures. J Manag Stud 25:283-284 
Shrivastava P, Mitroff II, Miller D, Miglani A (1988) Understanding industrial crises. J Manag Stud 25:285-303

Sirmon DG, Hitt MA (2003) Managing resources: linking unique resources, management, and wealth creation in family firms. Entrep Theory Pract 27:339-358

Smyrnios KX, Walker RH (2003) Australian family and private business survey. RMIT University, Melbourne

Stewart A, Hitt MA (2012) Why can't a family business be more like a nonfamily business? Modes of professionalization in family firms. Fam Bus Rev 25:58-86

Stinchcombe AL (1965) Social structure and organizations. In: March JG (ed) Handbook of organizations. Rand McNally \& Company, Chicago, pp 142-193

Thaler RH, Tversky A, Kahneman D, Schwartz A (1997) The effect of myopia and loss aversion on risk taking: an experimental test. Q J Econ 112:647-661

Trahms CA, Ndofor HA, Sirmon DG (2013) Organizational decline and turnaround: a review and agenda for future research. J Manag 39:1277-1307

Upton N, Teal EJ, Felan JT (2001) Strategic and business planning practices of fast growth family firms. J Small Bus Manag 39:60-72

Wallace JC, Little LM, Hill AD, Ridge JW (2010) CEO regulatory foci, environmental dynamism, and small firm performance. J Small Bus Manag 48:580-604

Wernerfelt B (1984) A resource-based view of the firm. Strateg Manag J 5:171-180

Westhead P, Howorth C (2006) Ownership and management issues associated with family firm performance and company objectives. Fam Bus Rev 19:301-316

White SB, Valley KL, Bazerman MH, Neale MA, Peck SR (1994) Alternative models of price behavior in dyadic negotiations: market prices, reservation prices, and negotiator aspirations. Organ Behav Hum Decis Process 57:430-447

Wilson N, Wright M, Scholes L (2013) Family business survival and the role of boards. Entrep Theory Pract 37:1369-1389

Winn J (1997) Asset productivity turnaround: the growth/efficiency challenge. J Manag Stud 34:585-600

Wiseman RM, Gómez-Mejía LR (1998) A behavioral agency model of managerial risk taking. Acad Manag Rev 23:133-153

Withers MC, Hillman AJ (2008) Director identities and the role of the board in organizational turnaround. Acad Manag Ann Meet Proc. doi:10.5465/ambpp.2008.33640675

Zahra SA, Hayton JC, Salvato C (2004) Entrepreneurship in family vs. non-family firms: a resource-based analysis of the effect of organizational culture. Entrep Theory Pract 28:363-381

Zahra SA, Pearce JA (1989) Boards of directors and corporate financial performance: a review and integrative model. J Manag 15:291-334

Zellweger TM, Astrachan JH (2008) On the emotional value of owning a firm. Fam Bus Rev 21:347-363

Zellweger TM, Kellermanns FW, Chrisman JJ, Chua JH (2012) Family control and family firm valuation by family CEOs: the importance of intentions for transgenerational control. Organ Sci 23:851-868 